\title{
One Step in the Right Direction - The New Horizontal Guidelines and the Restated Block Exemption Regulations
}

\author{
Claudia Seitz*
}

\section{Introduction}

In January 2011, the new guidelines on horizontal cooperation agreements and the restated block exemption regulations on research and development and on specialization and joint production of the European Commission entered into force. The aim of these new documents was to 'bring more legal certainty', to 'match market developments and respond to the needs of modern businesses' and to 'prevent competition concerns from arising from the outset, rather than only addressing concerns ex-post' commented the Director General of the Directorate General for Competition, Alexander Italianer, a few weeks after the new guidelines and regulations replaced the former documents. ${ }^{1}$

In addition to the goal to increase legal certainty the Commission intended to strengthen the innovation and competitiveness as well as to minimise agreements which are anticompetitive. According to Commission Vice President responsible for competition policy, Joaquín Almunia, 'one of the overarching goals of the new rules is to contribute to the Commission's Europe 2020 strategy, in particular by promoting innovation and competitiveness' whereas the 'new Guidelines and Block Exemption Regulations will give companies the necessary freedom to cooperate in a globalised market place, while at the same time minimising the risk of agreements that are harmful to industry and to consumers.'

This article will give a short overview of the new documents and assess to what extent the goal of the Commission may be achieved by the new guidelines and block exemption regulations.

For this purpose, the article will first outline the background of the new guidelines and regulations and give a short overview in this section, before summarising the

* Dr Claudia Seitz, MA (Kinǵs College London), is a Partner at Seitz \& Riemer Attorneys-at-Law, as well as a Lecturer of Law at the Universities of Basel, Switzerland and Constance, Germany. This article is based on a speech delivered at the Competition Law Conference of the University of Basel, Switzerland on 10 June 2011 on 'Information Exchange in Horizontal Cooperations under European and Swiss Law' and on a speech delivered at SwissHoldings, Competition Law Section, in Berne. Comments can be sent to claudia.seitz@seitzriemer.com or claudia.seitz@ unibas.ch.

\section{Key Points}

- In its new approach to horizontal agreements, the Commission expands the range of efficiency considerations that can be taken into account to assess practices.

- The objective is reached, partly at least, in the Regulation, which provides more clarity on issues important in that regard.

- But the Guidelines remain desperately vague potentially causing a 'chilling effect' towards efficient practices and creating a risk that firms may unconsciously engage in unlawful activities.

new block exemption regulations for research and development (Section II.A.) and for specialisation (Section II.B). Then the new guidelines on horizontal cooperation will be analysed in more detail in Section III. with a special focus on information exchange (Section III.A.) and standardisation (Section III.B.). This article will then analyse the practical consequences of these documents for companies in Section IV. with some specific remarks on the block exemption regulations for research and development and for specialisation (Section IV.A.) as well as on the new chapters in the horizontal guidelines on information exchange (Section IV.B.) and standardisation (Section IV.C.). Finally, a critical analysis on the new documents in Section V. will conclude this article.

\section{A. Background}

On 14 January 2011, the Commission's revised guidelines on the application of Article 101 TFEU to horizontal

1 Speech of Directorate General for Competition, Alexander Italianer, at Studienvereinigung Kartellrecht Conference on 1 March 2011 in Brussels, 'Doing business in Europe: the review of the rules on cooperation agreements between competitors', the speech is available at: http://ec. europa.eu/competition/speeches/text/sp2011_01_en.pdf.

2 Press Release of the European Commission, Commission adopts revised competition rules on horizontal cooperation agreements, 14 December 2010, IP/10/1702, < http://europa.eu/rapid/pressReleasesAction. do? reference $=\mathrm{IP} / 10 / 1702>$. 
cooperation agreements ('Horizontal Guidelines') ${ }^{3}$ were published in the Official Journal, along with the revised block exemption regulations on research and development ('R\&D BER'), ${ }^{4}$ and on specialization and joint production agreements ('Specialisation BER'). ${ }^{5}$ The new Horizontal Guidelines replace the 2001 Horizontal Guidelines. ${ }^{6}$ The previous guidelines that serve as a framework for horizontal cooperation agreements expired on 31 December 2010.

The new block exemption regulations entered into force on 1 January 2011 with a two-year transitional period, during which the former regulations remain in force for all agreements which meet the conditions of these regulations but which do not fall under the new rules. Agreements in these specific sectors are authorised provided the companies concerned have limited market power, which means a market share of no more than 25 per cent for research and development agreements and 20 per cent for specialisation or joint production agreements. ${ }^{7}$

\section{B. Overview}

The new Horizontal Guidelines provide an analytical framework for assessing the most common types of horizontal cooperation agreements, such as research and development, production, purchasing, commercialisation, standardisation, and information exchange. The two key features of the new Horizontal Guidelines are a new chapter on information exchange and a substantial revision of the chapter on standardisation agreements. The chapter on information exchange now provides general guidance in this area. ${ }^{8}$ Before the new Horizontal Guidelines entered into force companies had only some sector-specific guidance for information

3 Guidelines on the applicability of Article 101 of the Treaty on the Functioning of the European Union to horizontal cooperation agreements, 2011/C 11/01, 14/01/2011, OJ 11/1-72, < http://eur-lex. europa.eu/LexUriServ/LexUriServ.do?uri=OJ:C:2011:011:0001:0072:EN :PDF $>$.

4 Commission Regulation No 1217/2010 of 14 December 2010 on the application of Article 101(3) of the Treaty on the Functioning of the Eurpean Union to categories of research and development agreements, 18/12/2010, OJ L 335/36-42, < http://eur-lex.europa.eu/LexUriServ/ LexUriServ.do?uri=OJ:L:2010:335:0036:0042:EN:PDF>.

5 Commission Regulation No 1218/2010 of 14 December 2010 on the application of Article 101(3) of the Treaty to Categories of Specialisation Agreements, 18/12/2010, OJ L 335/43-47, < http://eur-lex.europa.eu/ LexUriServ/LexUriServ.do?uri=OJ:L:2010:335:0043:0047:EN:PDF>.

6 Commission Notice, Guidelines on the applicability of Article 81 of the EC Treaty to horizontal cooperation agreements ('Horizontal Guidelines'), 2001/C 3/02, 6/1/2001, OJ C 3/2-28, < http://eur-lex. europa.eu/LexUriServ/LexUriServ.do?uri=OJ:C:2001:003:0002:0030:EN $:$ PDF $>$.

7 For further information regarding the drafts, see Lübbig, Die Reform der EU-kartellrechtlichen Regeln über die horizontale Zusammenarbeit, [2011] EWS 5-8; Drexl, Früh, Mackenrodt, Picht, Pulyer, and Ullrich, exchange concerning liner shipping, which was comprised in the Maritime Guidelines of 2008. ${ }^{9}$

According to the Commission, the new documents update the application of the general competition law rules by the Commission to these specific forms of agreements so that companies can better assess whether their agreements are in line with the EU Regulations, the Commission's decisions and the jurisdiction of the EU Courts. To finalise these new documents the Commission launched a public consultation on 4 May 2010 on the application of Article 101 TFEU to horizontal cooperation agreements, and published revised drafts of the Horizontal Guidelines and the new R\&D BER and Specialisation BER for comments.

The basic approach of all revised documents-the new block exemption regulations and the Horizontal Guidelines-is to give more detailed and clearer guidance for companies in the respective areas. ${ }^{10}$ The amendments, innovations, and enhancements will now be assessed in more detail.

\section{Restated Block Exemption Regulations}

Before the new regulations entered into force guidance was provided by two previous block exemption Regulations-the Commission Regulation (EC) No. 2659/ 2000 on Research and Development Agreements and the Commission Regulation (EC) No. 2658/2000 on Specialisation Agreements. The two block exemption regulations exempt research and development cooperation as well as specialization and joint production agreements from the general ban on restrictive business practices laid down in Article 101(1) TFEU,

Comments of the Max Planck Institute for Intellectual Property, Competition and Tax Law on the Draft Commission Block Exemption Regulation on Research and Development Agreements and the Draft Guidelines on Horizontal Cooperation Agreements, IIC (2010) 41, 948 965.

8 Concerning a short comment on the Horizontal Guidelines, [see Camesasca and Schmidt, 'New Horizontal Guidelines: Providing Helpful Guidance in the Highly Diverse and Complex Field of Competitor Cooperation and Information Exchanges' 2011 JECLAP 227-229].

9 Council Regulation (EC) No 1419/2006 of 25 September 2006, i.e. liner shipping services, cabotage and international tramp services' ('Maritime Transport Guidelines'). For additional information to these guidelines, see Bermig and Ritter, 'The new Guidelines on the application of Article 81 of the EC Treaty to the maritime sector' [2008] Competition Policy Newsletter 25-9; Guersent, The Guidelines on Maritime Transport Services, Speech at the European Maritime Law Organisation, Copenhagen 24 Ocotber 2008, < http://ec.europa.eu/competition/ speeches/text/sp2008_12_en.pdf $>$.

10 See Italianer, Speech at Studienvereinigung Kartellrecht Conference on 1 March 2011 in Brussels, the available at: $<$ http://ec.europa.eu/ competition/speeches/text/sp2011_01_en.pdf $>$. 
provided they meet all the conditions set out in these regulations.

\section{A. Research and Development Block Exemption Regulation}

The revised R\&D BER which entered into force on 1 January 2011 and expires on 31 December $2022^{11}$ replaces the former Block Exemption Regulation on Research and Development Agreements ${ }^{12}$ which expired on 31 December 2010. The objective of the new R\&D BER is to meet two requirements: ensuring effective protection of competition and providing adequate legal security for undertakings. ${ }^{13}$ The objectives should take account of the need to simplify administrative supervision and the legislative framework to as great an extent as possible. ${ }^{14}$

One of the key elements of the R\&D BER is the insight that certain research and development cooperation activities by small enterprises will not distort competition because of their small market power. Cooperation between competitors to jointly undertake and subsequently exploit R\&D activities in this case may promote technical and economic progress, especially where the parties contribute complementary skills, assets, or activities to the cooperation. ${ }^{15}$ Thus, the R\&D BER generally presumes for the application of Article 101(3) TFEU that below a certain level of market power the positive effects of research and development agreements will outweigh any negative effects on competition. ${ }^{16}$

As before, the R\&D BER provides an automatic exemption for joint research and development of products or technologies, as well as the horizontal specialisation or joint exploitation of those results under the condition that the parties' combined market share in the relevant product or technology market does not exceed 25 per cent. ${ }^{17}$ If the market share exceeds 25 per cent, the exemption will last a further two years following the year the threshold of 25 per cent was exceeded. ${ }^{18}$ If, however, the market share exceeds 30 per cent, the exemption will persist for one further year only. Another condition is that where the R\&D

11 Article 9 R\&D BER.

12 Commission Regulation (EC) No 2659/2000 of 29 November 2000 on the application of Article 81(3) of the Treaty to categories of research and development agreements, OJ L 304, 5/12/2000, 7.

13 R\&D BER, para. 4.

14 R\&D BER, para. 4.

15 R\&D BER, para. 8.

16 R\&D BER, para. 4.

17 Article 4, para. 2 R\&D BER.

18 The Commission noted at the time the new R\&D BER entered into force that 'with a $25 \%$ market share threshold, R\&D agreements are the most agreement provides only for joint $\mathrm{R} \& \mathrm{D}$, the parties must agree to give access to each others' pre-existing knowledge.

The new R\&D BER is characterised by the wider scope of its application. Most of the changes and amendments of the new R\&D BER will provide more clarity and legal certainty. ${ }^{19}$ The new regulation now covers not only activities carried out jointly by the involved companies but considers also so-called 'paidfor research agreements'. These sorts of agreements cover arrangements where one party merely finances the research carried out by another company. The R\&D BER is based on the presumption of the Commission that joint research and development activities have positive effects, especially in cases where the parties do not have market power.

Besides that, the possibility to jointly exploit the results of $R \& D$ activities has been extended. Parties to an $\mathrm{R} \& \mathrm{D}$ activity can now profit from the exemption where only one party sells the contract products on the basis of an exclusive licence by the other party.

Moreover, the revised R\&D BER takes into account 'patent ambush' cases. The Commission noted that a party's intellectual property rights shall not unduly impair the exploitation of the results of an R\&D agreement by the other parties and therefore an exemption under the new R\&D BER should be available if prior to starting the R\&D activity all parties agree that they will disclose in an open and transparent manner their existing and pending intellectual property rights relevant for the exploitation of the results by the other parties. ${ }^{20}$

\section{B. Specialisation Block Exemption Regulation}

The revised Specialisation BER also entered into force on 1 January 2011 and replaces the former Specialisation Block Exemption Regulation which expired also on 31 December 2010. The new Specialisation BER clarifies that the benefit of exemption may also apply even when one of the parties to the agreement only partly ceases its production. This enables a company that has two production plants for a certain product to close down one of its plants and outsource the output

favourably treated category of horizontal agreements as such agreements can lead to substantial efficiencies because they stimulate innovation', MEMO/10/676, para. 3/4.

19 MEMO/10/676, para. 14.

$20 \mathrm{MEMO} / 10 / 676$, para. 14. The Commission noted in this context that is has 'become apparent during the public consultation that there is no practical need for such a disclosure obligation as, in particular, potential patent ambushes in the context of R\&D agreements can be adequately addressed by the parties through private contractual agreements.' 
of the closed plant while still benefiting from the exemption under the Specialisation BER.

The new provisions also introduce a second market share threshold where the agreement concerns intermediary products. It provides that, where the products concerned by a specialisation or joint production agreement are intermediary products which one or more of the parties use for the production of certain downstream products which they also sell, the exemption is conditional upon a 20 per cent market share threshold downstream. In case of a higher market share such a specialisation or joint production agreement should not benefit from an exemption under the Specialisation BER since there may be a potential risk of closing off inputs for competitors at the level of the downstream products. In this case an individual assessment according to Article 101(3) TFEU is required.

The Specialisation BER provides 'safe harbours' for certain specialisation and joint production agreements below the market share threshold from the scope of Article 101 TFEU. In general three 'safe harbours' can be identified: (i) unilateral specialisation agreements, where one party agrees to cease or refrain from production and purchase the product from another party; (ii) reciprocal specialisation agreements, where two or more parties agree reciprocally to cease or refrain from production of certain different products and purchase them from another party; and (iii) joint production agreements, where two or more parties agree to produce certain products jointly.

\section{New Horizontal Guidelines}

On 4 May 2010 the Commission published draft regulations and guidelines for the assessment of cooperation agreements between competitors. ${ }^{21}$ The new Horizontal Guidelines ${ }^{22}$ replace the 2001 Horizontal Guidelines and contain two new elements: the former Guidelines did not deal with the exchange of information between competitors and the new Horizontal Guidelines amend the chapter on standardisation agreements.

21 Berg/Koebele, Round Up, [2010] JECLAP 444; Lübbig, 'Die Reform der EU-kartellrechtlichen Regeln über die horizontale Zusammenarbeit'

[2011] EWS 5; Möhlenkamp, 'Informationsaustausch als Wettbewerbsbeschränkung-Kriterien und Beweislast', FIW, Wettbewerbspolitik und Kartellrecht, 2010, 209.

22 Gehring/Mäger, 'Kartellrechtliche Grenzen von Kooperationen zwischen Wettbewerbern-Neue Leitlinien der EU-Kommission', [2011] Der Betrieb 398

23 Horizontal Guidelines, para. 2.

24 Horizontal Guidelines, para. 2.

25 Horizontal Guidelines, para. 3.
In the new Horizontal Guidelines the Commission acknowledges that horizontal cooperation can lead to substantial economic benefits, in particular if they combine complementary activities, skills, or assets. ${ }^{23}$ Horizontal cooperation can be a measure to share risk, save costs, increase investments, pool know-how, enhance product quality and variety, and launch innovation faster. ${ }^{24}$ On the other hand, however, horizontal cooperation agreements may lead to competition problems-for example if the parties agree to fix prices or output, to share markets, or if the cooperation enables the parties to maintain, gain, or increase market power-and thereby is likely to give rise to negative market effects with respect to prices, output, innovation, or the variety and quality of products. ${ }^{25}$

\section{A. Information Exchange}

Information exchange among competitors is one of the most sensitive and critical area of competition law and requires a careful consideration of all aspects. Agreements or concerted practices which have as their object or effect the prevention, restriction, or distortion of competition constitute a competition law infringement according to Article 101(1) TFEU. ${ }^{26}$ Thus, as a general rule, commercially sensitive information must not be exchanged with competitors, since companies must operate independently of their competitors. This general rule, however, is not easy to assess in all cases. In the light of increasing fines, companies and their legal advisors have frequently complained that they lack sufficient official guidance on how to structure information exchange without running the risk of infringing competition law. ${ }^{27}$ The chapter on information exchange is a new element in the 2011 Horizontal Guidelines. ${ }^{28}$ The problems in connection with exchange of information between competitors, however, form a classic area of legal uncertainty. As such, the question of the permissibility of information exchange has been discussed since several decades. ${ }^{29}$

Before the new Guidelines entered into force, companies looking for guidance might consult the

26 Jones, 'Left behind by modernisation? - restrictions by object under Article 101(1)' [2010] European Competition Journal 649.

27 Wagner-von Papp, 'Information Exchanges in the Draft Horizontal Cooperation Guidelines' [2011] KSzW 87-94.

28 Wagner-von Papp, 'Who is't that can inform me?-The Exchange of Identifying and Non-Identifying Information' [2007] ECLR 264.

29 For example Carle and Johnsson, 'Benchmarking and E. C. Competition Law' [1998] ECLR 74; Feldkamp, 'Statistische

Marktinformationsverfahren und das europäische Kartellrecht' [1991] EuZW 617; Wagner-von Papp, 'Wie “identifizierend' dürfen Marktinformationsverfahren sein?' [2005] WuW 732. 
Guidelines on the application of Article 81 of the EC Treaty to Maritime Transport Services (Maritime Transport Guidelines) ${ }^{30}$ which provided a framework for information exchange within the sector of maritime transport. ${ }^{31}$ However, this general framework was contained in a sector-specific context which lead to the question whether the chapter on information exchange was of general applicability. ${ }^{32}$ While it was generally assumed that this guidance would be applicable to information exchanges in other sectors as well, the exact degree of transferability remained a matter for speculation. $^{33}$

The Horizontal Guidelines now explicitly state that certain forms of information exchange may have, in itself, the object of restricting competition and that such information exchanges are not covered by the guidelines. This distinction between restriction by object or effect has recently been emphasised by the ECJ in T-Mobile ${ }^{34}$ and the Commission refers to this distinction in the new Horizontal Guidelines by focusing on agreements and practices having the object, rather than the effect, or restricting, distorting, or preventing competition. The Horizontal Guidelines make it clear that information exchanges which are restrictive by object are not covered by the Horizontal Guidelines, since these practices are per se illegal. Thus there is, in addition, no need to carry out analytical assessments in these cases in order to determine whether or not the exchange of information is caught by Article 101 TFEU.

Whereas information exchange may lead to substantial economic benefits, exchange may also, under certain circumstances, have the effect of reducing or removing uncertainty as to the future behaviour of the market players, with the result that competition between undertakings is restricted. A restriction of competition may occur if certain circumstances are present, such as a concentrated market structure and exchanges of commercially sensitive information.

- The market structure is to be assessed in view of the level of concentration and the structure of supply and demand, notably the number of competitors, the symmetry, and stability of their market shares and the existence of structural links between them.

30 Guidelines on the application of Article 81 of the EC Treaty to Maritime Transport Services, 2008/C 245/02, OJ C245/2, 26/9/2008, paras 38-59, para. 41 et seq.

31 Before the Maritime Transport Guidelines entered into force in 2008 parties of a cooperation agreement had to consult the Commission's $7^{\text {th }}$ Report on Competition Policy 1977. See Wagner-von Papp, 'Draft Guidelines on the Applicability of Article 101 TFEU to Horizontal Cooperation Agreements' [2010] JECLAP 422-424.

32 The scope of the Maritime Transport Guidelines was limited to the assessment of 'cooperation agreements in those maritime transport
- Whether information is sensitive depends on its age and the period to which it relates, its aggregated or individualised nature and the frequency of the exchange. It also depends on whether the information is public or not, although in some cases public information may be enhanced or combined or made more accessible in a way that makes it sensitive.

The exchange of historic data is unlikely to lead to a collusive outcome as it is unlikely to be indicative of the competitors' future conduct or to provide a common understanding on the market. ${ }^{35}$ The Horizontal Guidelines give no guidance to the question when information can be considered as 'historical'. Accordingly, the historical or recent nature of the information needs to be assessed on a case-by-case basis with regard to all other factors in the relevant market. In this context the Commission noted in the Horizontal Guidelines that the three key factors-age, level of aggregation, and frequency-will be assessed by the Commission as a whole rather than separately, because some factors may have an impact on others.

\section{B. Standardization}

According to the growing role of industry standards to facilitate innovation, the revised chapter on standardisation in the new Horizontal Guidelines sets out the criteria under which the Commission will not take issue with a standard-setting agreement. The chapter reflects more than ten years of experience with standardization agreements. The revised chapter on standardization is longer and more precise than the corresponding chapter in the 2001 Horizontal Guidelines. The new provisions clarify in detail how to assess the compatibility of standard setting systems with Article 101 TFEU.

The new chapter supports a standard-setting system that is open, transparent, and fair and increases as such the transparency of licensing costs for intellectual property rights as a basis for standards, like patents. For this reason the new Horizontal Guidelines set out the rules for standard setting systems on 'fair, reasonable and non-discriminatory terms', the so-called FRAND

services directly affected by the changes brought about by Council Regulation (EC) No 1419/2006 of 25 September 2006, i.e. liner shipping services, cabotage and international tramp services' (Maritime Transport Guidelines, para. 1).

33 Wagner-von Papp, 'Information Exchanges in the Draft Horizontal Cooperation Guidelines' [2010] KSzW, 87-94.

34 Case C-8/08 T-Mobile [2009] ECR I-4529.

35 Horizontal Guidelines, para. 90. 
criteria. ${ }^{36}$ According to the new Horizontal Guidelines, an effective standard-setting process should take place in a non-discriminatory, open, and transparent way so as to ensure competition on the merits and to allow consumers to benefit from technical development and innovation. ${ }^{37}$ One of the key elements of the standardization chapter is on effective access to standard-setting procedures and to intellectual property rights which provide certain technology in order to implement adopted standards.

The new and revised chapter on standardisation defines some criteria under which standardisation agreements will not be considered as anticompetitive and as such defines some 'safe harbours' for industry practice. With a view to providing clear and useful guidance, the Commission adopted this 'safe harbour' approach: if the standard-setting process complies with the defined principles, it should normally not fall within Article 101(1) TFEU whereas standard setting processes that do not remain within the 'safe harbour' are not presumed to be illegal. $^{38}$ Outside the 'safe harbours' companies are required to analyse the standard-setting conditions in a self-assessment according to Article 101(3) TFEU.

The revised chapter defines as the two most important conditions for safe harbour exceptions under Article 101(1) TFEU the faith disclosure of intellectual property rights for the standardisation technology as well as access to standards according to the FRAND conditions. For the 'safe harbour' exception the criteria are (i) the requirement of unrestricted access and participation of all interested companies; ${ }^{39}$ (ii) transparency and the good faith disclosure of standardessential IPR's; ${ }^{40}$ (iii) the voluntariness of participation in the standardization technology; ${ }^{41}$ and (iv) access to the standard on FRAND terms. ${ }^{42,43}$

In addition, the revised chapter on standardisation provides detailed guidance on standardisation agreements that do not fulfil the criteria for 'safe harbours' and will be considered anticompetitive under Article 101 TFEU. As such the two most important elements of the standardization chapter cover the 'safe harbour' standardization agreements on the one hand and on the other hand the effects-based assessment of standardisation agreements outside the scope of the 'safe harbour' exception.

\footnotetext{
36 Barthelmeß and Gauß, 'Die Lizenzierung standardessentieller Patente im Kontext branchenweit vereinbarter Standards unter dem Aspekt des Art. 101 AEUV’ [2010] WuW 626-36; Layne-Farrar, Padilla and Schmalensee, 'Pricing Patents for Licensing in Standard-Setting Organizations: Making Sense of FRAND Commitments' [2007] 74 Antitrust Law Journal 671.

37 See Schellingerhout and Cavicchi, 'Patent ambush in standard-setting: the Commission accepts commitments from Rambus to lower memory chip royalty rates' [2010] 1 Competition Policy Newsletter 32, 36.
}

\section{Practical consequences for companies}

\section{A. Block Exemption Regulations on R\&D and Specialisation}

In general the revised new block exemption regulations-the R\&D BER and the Specialisation BERcontain useful clarifications in comparison to the former versions of these guidelines. As such they will bring additional value to the companies and their advisors and create 'safe harbours' for certain defined types of research and development agreements as well as specialisation agreements which are covered by the revised block exemption regulations.

\section{Specialisation block exemption regulation}

As such the revised block exemption regulations define certain 'safe harbours' for an exemption from Article 101 TFEU. These 'safe harbours' provide companies with a degree of legal certainty. Outside the scope of the 'safe harbours' there is, however, no presumption that agreements will automatically be considered anticompetitive under Article 101 TFEU. In this case, agreements need to be assessed individually on a caseby-case basis to determine whether they will fall within the exceptions of Article 101(3) TFEU.

The self-assessment in this case depends on the relevant market as well as on the possibility of illustrating that each of the cumulative conditions of Article 101(3) TFEU-efficiency gains, indispensability, passon of benefits to consumer, and no elimination of competition-is met. Regarding efficiency gains, the Specialisation BER recognises that specialisation and joint production agreements may have a pro-competitive effect if they permit parties to benefit from economies of scale that would not have been available to each party individually. Cooperation may also result in improved production technology and an improved product quality.

The condition of indispensability, however, could create a hurdle for companies in the self-assessment process. The Specialisation BER states that joint commercialisation of products could be considered as problematic. In cases where a joint commercialisation of products cannot be shown as indispensable for

\footnotetext{
38 See van der Walle de Ghelcke, 'The Commissiońs New Guidance on Standardisation' [2010] JECLAP 352-355.

39 Horizontal Guidelines, para. 281.

40 Horizontal Guidelines, para. 282.

41 Horizontal Guidelines, para. 293.

42 Horizontal Guidelines, para. 283.

43 See van der Walle de Ghelcke, 'The Commission's New Guidance on Standardisation’ [2010] JECLAP 352-355.
} 
achieving efficiency gains, this could create some uncertainty as to the question of whether the agreement may be exempted or not.

In order to fulfil the condition of passing-on benefits to consumers the specialisation or joint production agreement must grant consumers a fair share of the benefit resulting from the efficiency gains. This should be easy to prove if the agreement leads to lower prices or better quality of the products. Finally, the agreement must not eliminate competition in respect of a substantial part of the products.

\section{R\&D Block Exemption Regulation}

The revised R\&D BER exempts several research and development agreements from the general prohibition under Article 101(1) TFEU. ${ }^{44}$ As such there are several 'safe harbours' for companies in this area, which comprise agreements for (i) the carrying out of joint research and development; (ii) agreement for joint research and development combined with an agreement for joint commercialisation of joint research and development results; (iii) agreements that provide commercialisation by one party under an exclusive licence; and (iv) agreements which oblige one party to carry out research and development work for the other party.

\section{B. Information exchange}

The practical implications of the new Horizontal Guidelines on information exchange differ regarding the form of information exchange. There are too many forms of information exchange depending on the various industries and the companies to build categories for all of them. The typical practices of direct information exchange, however, may include for example (besides direct discussions between competitors or through trade associations) different forms of information exchange such as data exchange through black box systems, market specific panels, distribution panels, industry research, governmental sources, customs data, or field force surveys. How different the forms of information exchange may be even in these traditional forms of exchange will be illustrated on the basis of the following examples of some typical forms of information exchange.

\section{Black box data exchange systems}

The procedure referred to with this term is the marketsize assessment based on actual sales numbers on a predetermined schedule. Sometimes it is set-up by specific associations or, if independently, by a group of compa- nies representing the biggest share of the market. The participating companies provide their sales numbers in a predefined structure to a trustee who compiles the market value report accordingly. The individual company would be able to identify its own share within the total market and each partition of the structure in this report. In this specific case of data exchange, entering information where a company can learn about market share, sales volume, or price information from individual competitors is not allowed.

\section{Panel exchange systems}

Panel exchange systems refer to the data collection by an industry association or a private market research company. The exchange system may return information about products, product application, and eventually qualitative information. The market research company is either contracted by an open group of companies interested in this type of data or has actively sold its offer to a number of companies. The number of companies participating is mainly limited to the bigger players due to the rather high investment required.

\section{Distribution panel}

This sort of information exchange system refers to data collection at distributor or retailer level, usually done by a market research company. The information collected can be looking at sales volumes or stock levels at different levels of detail (brand, product category, etc.). This information can be grouped by product, product types or selling companies, depending on the contractual agreements.

\section{Industry research}

This procedure refers to a data collection process conducted by consultants or market research firms. During this process the consultants or firms gather market information from various sources (manufacturers, distributors, associations, advisors, consultants, customers etc.). The information collected may target different levels of detail (total market, sector values, specific values, key products, etc.). Through a process of crosscomparing, aggregation, and disaggregation the market research firms synthesise a market picture at a sales of consumption level.

\section{Government sources}

In some industries national statistical bureaus may conduct specific surveys for certain products or services as well. The purchase or use of specific products or service could be the subject of or part of these surveys. 
Results are usually published by the governmental source and some results are generally made available to the public.

\section{Customs data}

In addition, in some industries, national customs keeps records on the export and import of specific products. The trade balance plus eventual domestic sales can give a good indication of the overall market value in sales terms. Depending on the availability of customs data, detailed conclusions on manufacturing or distributing companies as well as on product type or even active ingredients might be revealed.

In all of these typical forms of information exchange it is evident that it is illegal to exchange information which would be considered commercially sensitive or secret or to allow access to individualised competitive information. It is also critical to make use of nonpublic information (sources) and to exchange information on future market or market share development expectations. Because of the limited aggregation of sensitive information, it is also not permissible to enter into an exchange of information if it is substantially restricted to a limited number of participants only. It is also clearly not permissible to grant access to individualised competitive information, to make use of nonpublic sensitive information and to exchange information on future market or market share development.

However, there are a various specific questions relating to the specific form of exchange. In the case of data exchange through a black box data exchange system, for example, the question may arise whether there is enough data aggregation granted by a system which does not allow the parties to learn about market share, sales volume, or price information from individual competitors. The panel exchange system may raise the question of whether the number of companies participating in this exchange system is too limited or whether restriction to the bigger players may lead to concerns. In addition any form of investment or any other form of payment in order to acquire the information may lead to the question of whether this information may still be considered as public information since several-at least smaller-companies may not be able to afford these investment and, as a result, will be excluded from this information. Due to the rather high investment required, companies run the risk that the exchange may be considered as non-public information which might not be available to all competitors on the market.

45 See Wagner-von Papp, 'Information Exchanges in the Draft Horizontal Cooperation Guidelines' [2010] KSzW 87.
While there are some information exchanges that are clearly permissible, and some information exchanges that are clearly anticompetitive and therefore prohibited, cases which do not fall into one of these categories are difficult to assess. These cases fall into the so-called 'grey zone. ${ }^{45}$ While the Horizontal Guidelines explain some examples of illegal information exchange-which are rather easy to assess since they constitute forms of anticompetitive information exchange-the new Horizontal Guidelines give few examples of what can be considered as pro-competitive and legal information exchange. Thus, the competitive assessment of information exchanges may not be straightforward. ${ }^{46}$

In addition, besides these traditional types of information exchanges there are various other forms of information exchange which are not covered by the new Horizontal Guidelines but which are of practical importance. One area of information exchange which is not explicitly covered by the new Horizontal Guidelines is information exchange in the context of M\&A projects, especially in the context of due diligence activities or during the phase between signing and closing. It is clear that 'gun jumping' is not allowed, however, the question remains how the closing of a deal may be prepared without any information exchange between the involved companies of a merger.

There is no indication in the text of the new Horizontal Guidelines that, for example, during due diligence processes the Horizontal Guidelines will not apply or at least what kind of information is exchangeable in the context of merger deals. This means that as a general rule competitors should not exchange sensitive information such as, for example, prices, discounts, conditions of supply, profit margins, cost structures, calculation practices, distribution practices, territories, and customers. Other forms of information gathering during a due diligence process, such as information on the future strategies of the target as well as other data required to evaluate the target are not easy to assess under the new Horizontal Guidelines. In this case the Commission should take into account when assessing such cases that there may be legitimate business reasons for this form of 'exchange' which may not be anticompetitive. This approach, however, will not help the parties of merger at the time of merger negotiations and notifications.

\section{Standardisation}

The new chapter on standardisation agreements is substantially revised and amended. The new chapter now

46 Wagner-von Papp, 'Information Exchanges in the Draft Horizontal Cooperation Guidelines', [2010] KSzW 87, 88. 
comprises-when compared to the chapter in the former guidelines-helpful clarifications. In addition, it contains 'safe harbour' conditions under Article 101(1) TFEU which, together with the new clarifications, create real value for companies.

Although the new chapter results in considerable advantages there are still some open questions. It is unclear, for example, whether the FRAND rules will apply for small standard-setting groups in the same way. And there is no indication in the new chapter regarding the consequences under Article 101 TFEU if one of the participations of a standardisation agreements fails to license the technology on FRAND terms. From a legal point of view this could lead to a violation of Article 101 TFEU, which could lead to the standardisation agreement being nullified according to Article 101(2) TFEU. In practice, however, this would not help greatly, if the standard is already widely applied by companies. In addition there are not many indications for selfassessment in cases where a standardisation agreement falls outside the scope of a 'safe harbour'. If the standardisation agreement falls within Article 101(1) TFEU, it could be exempted under Article 101(3) TFEU. Unfortunately, the guidance on this point is rather limited and often repeats general priniciples that were discussed under the section on Article 101(1) TFEU. ${ }^{47}$

\section{Critical analysis and conclusions}

\section{A. Critical analysis}

\section{Restated block exemption regulations}

In general the Specialisation BER and the R\&D BER do not represent a radical departure from the previous regulatory regime for specialisation and joint production agreements and for research and development agreements. The scope of the exemptions, however, is broader than the exemptions provided under the previous block exemption regulations. For $R \& D$ agreements, for example, the new R\&D BER applies also to paid R\&D services which were not covered by the former regulation. The former regulation also did not clearly extend the exemption to agreements providing for the commercialisation of the results by one party only, based on an exclusive licence.

Besides this useful extension of the scope of 'safe harbours' the amendments of the regulations are relatively minor in nature. They could be considered as updates of the previous practice of the Commission

\footnotetext{
47 See van der Walle de Ghelcke, 'The Commissiońs New Guidance on Standardisation' [2010] JECLAP 352-355.

48 Horizontal Guidelines, para. 2.
}

rather than a wholesale change of the applicable rules. Therefore, companies that are familiar with the previous block exemption regulations should not find it difficult to navigate the revised Specialisation BER and R\&D BER in general.

\section{Horizontal Guidelines}

There is no doubt that horizontal cooperation agreements such as information exchanges can lead to efficiencies and pro-competitive effects. The new Horizontal Guidelines notice that 'horizontal cooperation agreements can lead to substantial economic benefits, in particular if they combine complementary activities, skills or assets. ${ }^{48}$ They ascertain further that horizontal cooperation can be a means to share risk, save costs, increase investments, pool know-how, enhance product quality and variety, and launch innovation faster. ${ }^{49}$ Thus, horizontal cooperation agreements are also not regarded as per se illegal by the revised Horizontal Guidelines. However, in order to bring these pro-competitive effects and efficiencies to live legal certainty is required.

Without this legal certainty companies will still run the risk of infringing competition law which will result in heavy fines and severe other consequences in the form of high compensation claims. In this context, it is a logical consequence that companies tend to be overcautious. This leads to a scenario which is affected by 'over compliance by companies. This, on the other hand, will implicate less efficiencies and pro-competitive effects.

A solution would have been the introduction of certain de-miminis thresholds, at least for agreements without any restriction by object. It may be the case that information exchange which is based on legitimate business reasons and which do not restrict competition by object may not have any anti-competitive effect and, thus, may be unproblematic from a competition law point of view. It should be sufficiently clear, for example, that information exchange is permissible where undertakings in an atomistic market that do not collectively control a large market share want to aggregate their information about the development of consumer demand for a certain product, so as to arrive at significant industry statistics. ${ }^{50}$ In this context the new Horizontal Guidelines notice that if the parties have a low combined market share, the horizontal cooperation agreement is unlikely to give rise to restrictive effects on competition with the meaning of Article 101(1) and, normally, no further analysis will be required'. This notice, however, does not gives sufficient official guidance on how to assess what is

49 Horizontal Guidelines, para. 2.

50 Wagner-von Papp, 'Information Exchanges in the Draft Horizontal Cooperation Guidelines' [2010] KSzW 87-94. 
meant by 'a low combined market share'. The new Horizontal Guidelines do not give any indication on this specific question.

The Guidelines further state "what is considered to be a "low combined market share" depends on the type of agreement in question'. In this respect the Horizontal Guidelines refer to the De Minimis Notice. ${ }^{51,52}$ The question is whether the 'low combined market share' for horizontal cooperation agreements is the same as mentioned in the De Minimis Notice or whether it is higher for such kind of agreements. If the market share is the same then the new Horizontal Guidelines do not bring extra value, since the thresholds are already established in the De Minimis Notice. If the thresholds are higher, then the question still remains: what is meant by a 'low combined market share'.

It seems, however, that it may be not the same, since the new Horizontal Guidelines notice that if one of just two parties has only an insignificant market share and if it does not possess important resources, even a high combined market share normally cannot be seen as indicating a likely restrictive effect on competition in the market. ${ }^{53}$ Thus, the notice in the Horizontal Guidelines is logical: 'Given the variety of horizontal cooperation agreements and the different effects they may cause in different market situations, it is not possible to give a general market share threshold above which sufficient market power for causing restrictive effects on competition can be assumed. ${ }^{54}$ This is a logical consequence but does not provide legal certainty. This could lead to a situation where companies may not agree on efficient horizontal cooperation agreements above the thresholds of the De Minimis Notice.

Besides the lack of any de minimis thresholds beyond the De Minimis Notice, the new chapter on information exchange does not provide additional 'safe harbours' for certain forms of information exchange. Neither do the guidelines define what is meant, for example, by 'historic information' or which level of 'aggregation' is not considered as problematic, nor do the new Horizontal Guidelines give any indication on the question what is really meant by 'public information'. The refusal to establish 'safe harbours' leads to the result that the new chapter on information exchange could be

51 Commission Notice on agreements of minor importance which do not appreciably restrict competition under Article 81(1) of the Treaty establishing the European Community (de minimis) OJ C 368, 22/12/ 2001, 13-15.

52 See Horizontal Guidelines, para. 44.

53 Horizontal Guidelines, para. 44.

54 See Horizontal Guidelines, para. 44. regarded as largely worthless in the eyes of the practitioner. $^{55}$

Another critical area seems to be the public announcement of company information. Where a company announces publicly, for example in the internet or via the press, its future strategy on new products, capacity, or pricing, this could be regarded as a form of information exchange, since competitors could use this information to adapt their own capacity or pricing strategy accordingly. Not every public announcement of company information, however, may be anticompetitive. There are often legitimate business reasons behind the announcement such as, for example, the publication of a price list of distributors of a specific product. Competition authorities need to consider carefully in this case whether the publication of certain company information is clearly anticompetitive.

These examples illustrate the difficulties in establishing 'hard and fast rules' which apply in all cases of information exchange. In practice it is sometimes difficult to distinguish between information exchange that is anticompetitive and will restrict competition on the one hand and information exchange that could provide a transparency to the market which is actually procompetitive with some benefits for competition and the consumer.

It is clear that transparency in the market could support tacit collusion, coordination within a cartel, and monitoring compliance with a cartel. Knowledge of a competitor's strategies on pricing or capacity removes the uncertainty in the market that underpins competition. As such, information exchange has its assets and drawbacks: information exchange can be both-depending of the circumstances of each casepro-competitive and anticompetitive. On the one hand it is a basic element of benchmarking and competition, on the other hand it may lead to massive anticompetitive results, such as anticompetitive agreements or collusive behaviour up to hard core restrictions. This makes it very difficult to establish clear-cut rules for the assessment of information exchange in guidelines which are generally applicable. From an analytical point of view, the difficulties in assessing information exchange between competitors are based on the

55 Wagner-von Papp, 'Information Exchanges in the Draft Horizontal Cooperation Guidelines' [2010] KSzW 87, 91. However, Wagner-von Papp does not consider this as a 'damning critique on the Guidelines', since the 'factors determining the harmfulness of information exchanges are "compensatory" in that there is no single factor which cannot be compensated by other factors, alone or in combination'. 
'janus-face' of market transparency, which also cannot be clearly categorised as pro- or anticompetitive.

\section{B. Conclusions}

Indeed, the new and revised chapters in the Horizontal Guidelines as well as the revised block exemption regulations are clearly a step in the right direction to the extent that they provide additional guidance. This guidance, however, does not remove the uncertainty completely and gives advice to a certain extent only. In general, the Commission is adopting a more conservative stance. The guidelines simply provide a general analytical framework, which should be adapted to the particular circumstances in a given case. Although the documents comprise some examples, the guidelines are meant to provide indications regarding the reasoning and relevant factors only.

Clearly, the Commission seemed to be anxious and tried to avoid making any specific statements regarding 'safe harbours' or further de minimis thresholds that could be seen as specific 'safe harbours'. Instead, the tone adopted is somewhat uncommitted and the substance goes no further than what has already been established by existing policy, Commission decisions and case law from the EU Courts. Maybe one of the reasons for this is that the Commission sought to eliminate the creation of 'loopholes' by defining provisions that are too specific but which could not comprise all possible cases of information exchange. This means that there are no hard and fast rules which could be easily applied to all cases in daily business. The assessment is still focused on a case-by-case analysis of each single instance.
Although it is fundamentally important for companies to be familiar with the revised rules whenever they cooperate with competitors and while mistakes can have potentially severe consequences, the new documents may not be precise enough to clearly assess the question of whether a cooperation is allowed in a specific case or not. The difference between permissible cooperation and an illegal cartel can often be quite difficult to discern. In this respect, as Director General Alexander Italianer commented on the new Horizontal Guidelines 'most of the time competitors compete, but cooperation can nevertheless be key in developing and marketing existing or new products, ${ }^{56}$ it is a good sign. A clear legal assessment in any one single case, however, may remain difficult if not impossible.

This means for the companies that there still remain some cases of information exchange which are not clearly identifiable as anti- or pro-competitive. As such, companies that participate in information exchange are still walking on thin ice. This creates 'chilling effects' which may lead to 'over compliance' by the companies. As such, efficiencies which could be created by some forms of cooperation may never come into existence. This should be kept at the back of one's mind when assessing cases under the revised guidelines and regulations. As such the new documents are one step in the right direction since they try to give more guidance - it remains to whish that there will be further steps in this direction in the near future.

doi:10.1093/jeclap/lpr061 Advance Access Publication 14 September 2011
56 Speech at Studienvereinigung Kartellrecht Conference on 1 March 2011 in Brussels, the speech is available at: < http://ec.europa.eu/competition/ speeches/text/sp2011_01_en.pdf>. 